\title{
Response to Michiel Alexander de Raaf et al.
}

\author{
Qifeng Yang ${ }^{1} \cdot$ Chi Hou $^{1,2} \cdot$ Kai Yang ${ }^{1} \cdot$ Jian Wang ${ }^{1,2,3} \cdot$ Yuqin Chen ${ }^{1}$
}

Received: 28 October 2020 / Revised: 2 December 2020 / Accepted: 2 December 2020 / Published online: 14 January 2021

(C) The Japanese Society of Hypertension 2021

We sincerely appreciate your interest in and opinions about our article. Here is our reply.

Regarding your concerns about potential emphysema, we believe the histopathological assessments in our study (Fig. 2A from the original article which is commented), including hematoxylin and eosin staining, Masson's trichrome staining, Verhoeff-Van Gieson staining, and immunofluorescence staining for caspase-3, have provided convincing evidence that no significant emphysema was observed in either the Sugen-only rats or Sugen/hypoxia $(\mathrm{SuHx})$ rats, even at 8 weeks, which is contrary to the results in some of the previous studies [1-3].

Regarding the occlusive intimal changes, Toba et al. previously showed significant pulmonary vascular luminal obstruction in SuHx-PH (pulmonary hypertension) rats [4]. Similarly, our data also indicated pulmonary vascular luminal obstruction, reflected by the scoring performed on Verhoeff-van Gieson-stained slides as follows: no evidence of neointimal formation (grade 0), partial luminal occlusion $(<50 \%$; grade 1$)$, and severe luminal occlusion $(>50 \%$; grade 2) (Fig. 3A from our original article which is commented).

It is well known that the pulmonary arterial pressure (PAP) can be predicted and calculated based on the cardiac output $(\mathrm{CO})$ and pulmonary vascular resistance (PVR) with the formula $\mathrm{PAP}=\mathrm{CO} \times \mathrm{PVR}$. The intraluminal radius of pulmonary arterioles plays a decisive roles in PVR [5].

Yuqin Chen

yqchen@gzhmu.edu.cn

1 State Key Laboratory of Respiratory Disease, National Clinical Research Center for Respiratory Disease, Guangdong Key Laboratory of Vascular Disease, Guangzhou Institute of

Respiratory Health, The First Affiliated Hospital of Guangzhou Medical University, Guangzhou, Guangdong, China

2 Department of Neurology, Guangzhou Women and Children's Medical Center, Guangzhou, China

3 Section of Physiology, Division of Pulmonary, Critical Care and Sleep Medicine, University of California, San Diego, La Jolla, CA, USA
However, the number of vessels in the lung affects the cross-sectional area for blood circulation. A decreased number of vessels also leads to increased PVR. It has been reported that vascular endothelial growth factor (VEGF) and VEGF receptor 2 are critical factors affecting endothelial cell survival $[6,7]$ and angiogenesis $[8,9]$. Therefore, Sugen may not only lead to pulmonary vascular occlusion but also induce damage and the loss of microvessels, which would mean that the degree of pulmonary vascular remodeling cannot fully explain the degree of right ventricle (RV) failure in the Sugen-only model. There is evidence that microvascular alterations occur in the RV $[10,11]$. In the Sugen model, the RV microvasculature is dysfunctional and not comparable [12]. Therefore, the reduction in $\mathrm{CO}$ in Sugen-only rats to almost the same degree as that observed in SuHx rats was supposedly caused not only by the change in afterload but also by the direct toxic effect of Sugen.

The greatest significance of our study is that it provides more relevant models for studying the pathogenesis of pulmonary hypertension caused by endothelial dysfunction and pulmonary vascular remodeling with different severities.

\section{Compliance with ethical standards}

Conflict of interest The authors declare that they have no conflict of interest.

Ethics approval The manuscript has been approved by all authors for publication. This study was approved by the ethics committee of the First Affiliated Hospital of Guangzhou Medical University.

Publisher's note Springer Nature remains neutral with regard to jurisdictional claims in published maps and institutional affiliations.

\section{References}

1. Jiang B, Deng Y, Suen C, Taha M, Chaudhary KR, Courtman DW, et al. Marked strain-specific differences in the SU5416 rat model of severe pulmonary arterial hypertension. Am J Respir Cell Mol Biol. 2016;54:461-8. 
2. Nicolls MR, Mizuno S, Taraseviciene-Stewart L, Farkas L, Drake JI, Al Husseini A, et al. New models of pulmonary hypertension based on VEGF receptor blockade-induced endothelial cell apoptosis. Pulm Circ. 2012;2:434-42.

3. Vitali SH, Hansmann G, Rose C, Fernandez-Gonzalez A, Scheid A, Mitsialis SA, et al. The Sugen 5416/hypoxia mouse model of pulmonary hypertension revisited: long-term follow-up. Pulm Circ. 2014;4:619-29.

4. Toba M, Alzoubi A, O'Neill KD, Gairhe S, Matsumoto Y, Oshima $\mathrm{K}$, et al. Temporal hemodynamic and histological progression in Sugen5416/hypoxia/normoxia-exposed pulmonary arterial hypertensive rats. Am J Physiol Heart Circ Physiol. 2014;306:H243-250.

5. Kuhr FK, Smith KA, Song MY, Levitan I, Yuan JX. New mechanisms of pulmonary arterial hypertension: role of $\mathrm{Ca}(2)(+)$ signaling. Am J Physiol Heart Circ Physiol. 2012;302:H1546-62.

6. Gerber HP, McMurtrey A, Kowalski J, Yan M, Keyt BA, Dixit V, et al. Vascular endothelial growth factor regulates endothelial cell survival through the phosphatidylinositol $3^{\prime}$-kinase/Akt signal transduction pathway. Requirement for Flk-1/KDR activation. J Biol Chem. 1998;273:30336-43.

7. Sundberg C, Nagy JA, Brown LF, Feng D, Eckelhoefer IA, Manseau EJ, et al. Glomeruloid microvascular proliferation follows adenoviral vascular permeability factor/vascular endothelial growth factor-164 gene delivery. Am J Pathol. 2001;158:1145-60.

8. Voelkel NF, Gomez-Arroyo J. The role of vascular endothelial growth factor in pulmonary arterial hypertension. The angiogenesis paradox. Am J Respir Cell Mol Biol. 2014;51: 474-84.

9. Baluk P, Lee CG, Link H, Ator E, Haskell A, Elias JA, et al. Regulated angiogenesis and vascular regression in mice overexpressing vascular endothelial growth factor in airways. Am J Pathol. 2004;165:1071-85.

10. Vonk-Noordegraaf A, Haddad F, Chin KM, Forfia PR, Kawut SM, Lumens J, et al. Right heart adaptation to pulmonary arterial hypertension: physiology and pathobiology. J Am Coll Cardiol. 2013;62:D22-33.

11. Vonk Noordegraaf A, Westerhof BE, Westerhof N. The relationship between the right ventricle and its load in pulmonary hypertension. J Am Coll Cardiol. 2017;69:236-43.

12. Bogaard HJ, Natarajan R, Henderson SC, Long CS, Kraskauskas $\mathrm{D}$, Smithson L, et al. Chronic pulmonary artery pressure elevation is insufficient to explain right heart failure. Circulation. 2009;120:1951-60. 